\title{
Minimally Invasive Wireless Spinal Cord Stimulation: A Novel Approach for Refractory Angina in Women
}

\author{
Prasad S. S. V. Vannemreddy ${ }^{1,4}$ Laura Tyler Perryman ${ }^{2}$ \\ ${ }^{1}$ Department of Neurosurgery, University of Illinois at Chicago, \\ Illinois, United States \\ 2 Stimwave Technologies, Miami, Florida, United States \\ ${ }^{3}$ Department of Cardiology, Nizam's Institute of Medical Sciences, \\ Hyderabad, Telangana, India \\ ${ }^{4}$ Consultant Neurosurgeon, Apollo Hospitals, Hyderabad, \\ Telangana, India
}

Ind J Car Dis Wom 2019;4:207-212

\author{
Address for correspondence Prasad Vannemreddy, MBBS, MS, \\ MCh, Department of Neurosurgery, University of Illinois at Chicago, \\ 912 S Wood street, IL 60612, United States \\ (e-mail: Prasad4458@hotmail.com).
}

\begin{abstract}
Keywords

- angina pectoris

- chronic pain

- neuromodulation

- wireless

- spinal cord stimulation
\end{abstract}

Refractory angina (RA) persists even after thorough treatment for coronary artery disease. In such difficult situations, neuromodulation offers effective alternative management. One such minimally invasive procedure is spinal cord stimulation (SCS), a rapidly evolving therapy in the treatment of pain management. SCS has been in use to control RA and in some reports exhibited beneficiary results. However, several equipment-related complications have been reported, mainly attributed to the bulky implant material and the implantable pulse generator.

Recent advancements in minimally invasive surgical methods and electronics resulted in implantable electrode coupled with nanotechnology-operated antenna. This is the smallest pulse generator in the field of neuromodulation at present.

The equipment in this minimalistic approach involved percutaneous implantation of a single electrode (with embedded microelectronic sensors) at the required anatomical location, operated by means of wireless antenna placed in the vicinity of the implant and moderated by both the patient as well as the clinician. The advantage with the nanoeletrode stimulation include reduced surgical trauma/health care costs/surgical duration and improved cosmetic result, especially in women.

This minimalistic wireless neuromodulation (WNM) has been successful in the management of chronic pain in failed back surgery syndrome (FBSS), herpetic neuralgia, complex regional pain syndrome (CRPS), and facial pain. SCS with WNM could increase the indications in RA and possibly improves the outcome of these patients.

\section{Introduction}

Conventional therapy and results for stable angina have been directed predominantly on men, while fewer women get enrolled in prospective clinical trials, for various reasons. However, cardiovascular disease (CVD) remains a leading killer in women and death rates due remain higher in women compared with men. ${ }^{1}$ Additionally, research has shown that women with stable (defined as retrosternal chest pain associated with exertion or stress and relieved by nitroglycerin or rest) typical angina exhibit more symptoms and functional impairment. ${ }^{2,3}$
Manheimer et al defined refractory angina (RA) as "a chronic condition characterized by the presence of angina caused by coronary insufficiency in the presence of coronary artery disease which cannot be controlled by a combination of medical therapy, angioplasty, and coronary bypass surgery. The presence of reversible myocardial ischemia should be clinically established to be the cause of the symptoms. Chronic is defined as a duration of more than 3 months." 4

Some of the many reasons for failed interventions in RA include anatomy of the coronary arteries, poor response to
(C2019 Women in Cardiology and Related Sciences

\section{License terms}

(®)(1) $\Theta$ 
coronary bypass procedures or angioplasty, existing comorbidities, and combination of these factors. ${ }^{4-6}$

Canadian health statistics disclose that $\sim 500,000$ Canadians suffer from $\mathrm{RA}^{7}$ while the American reports estimated that 600,000 to 1.8 million people have RA, with new annual addition of 75,000 patients. ${ }^{8,9}$

European studies reported annual incidence of 30,000 to 50,000 new cases. ${ }^{4,10}$ On the other hand, the United Kingdom estimated only 16,500 new cases per year in England and as such specific figures for the United Kingdom could not be defined. ${ }^{11,12}$

These patients suffer from severe pain in the chest resulting in frequent hospitalizations leading to higher health care costs and reduced health-related quality of life (HRQoL) reflecting an increased burden on the society. ${ }^{4,13}$

Multiple options are available to control the symptoms that include medications, sympathectomy, behavior therapy, neuromodulation methods including ganglion blocks, nerve blocks, and spinal cord stimulation (SCS)..$^{14-16}$

SCS mediates its effects by epidural stimulation which produces pain relief, reduced sympathetic tone, low myocardial oxygen perfusion, and increased microcirculation in the coronaries thereby controlling myocardial ischemia. ${ }^{17}$

\section{Spinal Cord Stimulation in Angina Pectoris}

SCS stimulates the dorsal columns and reduces transmission of nociceptive impulses along the spinothalamic tracts modulating several neurochemicals like $\beta$-aminobutyric acid (GABA) and $\beta$-endorphins with a resultant decrease in myocardial oxygen consumption. Several studies have established the effect of epidural SCS on sympathetic nervous system leading to reduced myocardial oxygen demands. ${ }^{18-20}$ SCS also improves homogenization of myocardial blood flow by improving coronary microvasculature dynamics. ${ }^{21,22}$

Additionally, SCS also modifies the capacity of intrinsic cardiac neuronal activity to facilitate relief from angina ${ }^{23}$ while the excitatory neuronal effects get suppressed during stimulation.

There is general consensus supported by systematic reviews as well as meta-analyses that SCS can alleviate angina symptoms and improve functional status without increasing mortality and morbidity. ${ }^{24,25}$

The physiological basis for neuromodulation in angina pectoris is as follows:

In 1975 Anpthorp et al demonstrated that sectioning of sympathetic nervous supply provided relief in $75 \%$ of patients with angina. ${ }^{26}$ Melzack and Wall later demonstrated gate control theory for pain based on the proposal that pain was conducted by small nociceptive c-fibers in the spinal cord. ${ }^{27}$ It took a couple of decades to demonstrate the benefits of SCS in chronic RA, when Murphy and Giles stimulated the spinothalamic tracts by placing a nerve stimulator connected to an epidural electrode pole to stimulate the dorsal horn interneurons with a low amplitude current. ${ }^{28}$ This stimulation inhibited nociceptive signals, producing pain relief.

In due course, several randomized studies supported the utility of neuromodulation in peripheral vascular disease (PVD) as well as $\mathrm{RA}^{29-33}$ albeit in smaller samples. ${ }^{25,34}$
Pan et al demonstrated the safety and efficacy of SCS in RA, wherein SCS improved exercise time, decreased medication, as well as disease perception with significant improvements in QoL. ${ }^{34}$

Historically, however, SCS in its conventional equipment form, has not been devoid of complications or limitations utilizing an implantable battery. Several patients have failed the stimulation and the SCS systems have had a long history of severe adverse events, mainly attributable to the implantable pulse generator (IPG) battery. ${ }^{35,36}$ A significant number of patients, almost $50 \%$, reportedly have failed the SCS trial, ${ }^{35-37}$ while additional failures came from complications contributed by the migration/fracture of the electrodes. IPG failures and complications added to this failed SCS therapy. Postoperative infection, hemorrhage, and painful operative wounds were frequently reported with IPG and its extension wires. Additionally, SCS cannot provide adequate pain relief in some anatomical locations in its conventional form due to its stimulation parameters. ${ }^{35-38}$

Several modifications to the SCS equipment have reduced adverse events, in an effort to improve the efficacy of the therapy, thus increasing the indications for neuromodulation. ${ }^{39}$ Some of these modifications include percutaneous implantation techniques, smaller/compact batteries with increased life of pulse generators, rechargeable batteries, and innovative anchoring methods. Additional advancement has been derived from the improvements in the application of nanomaterials and wireless power transfer techniques for clinical purpose.

\section{The Wireless Neuromodulation Apparatus}

This innovative implant has miniature components embedded in a single implant. The power transfer techniques utilize microantenna incorporated in to the electrode and activated by wireless approach via an externally placed power source.

\section{Implantable Neural Stimulator (INS)}

This stimulator is composed of an encasing sheath with the stimulating electrode array, which delivers electrical pulses to the target and an antenna- 1 configured to receive the energy-input from an externally placed antenna- 2 through electric radiative coupling. The second antenna remains physically away from the implant, INS lead, and communicates with the antenna- 1 by circuits designed to generate electrical pulses meant for stimulation of the target ( $\mathbf{F i g}$. 1a, $\mathbf{b})$.

The microimplant wireless power generator (WPG) on antenna-1 delivers the appropriate stimulation impulses, has 800 to $1350 \mu \mathrm{m}$ diameter, a very small compact size compared with the conventional SCS-IPG. The INS can have a variety of leads (with 4 or 8 contacts). Electrode can be

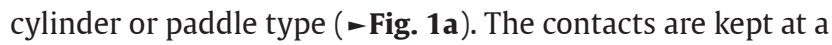
$3 \mathrm{~mm}$ distance apart on the electrode ( - Fig. $\mathbf{1 b}$ ).

Patient receives the implant, one or more, according to the required stimulation parameters and the target locations which gets coupled with the wireless receiver $(\boldsymbol{-}$ Fig. 2). The WPG remains in the vicinity of this INS, outside the patient body, as the power source, worn by the patient over a single layer of cloth ( - Fig. 3 ). Thus, there is only one electrode, a passive and wirelessly activated implant, placed inside the 


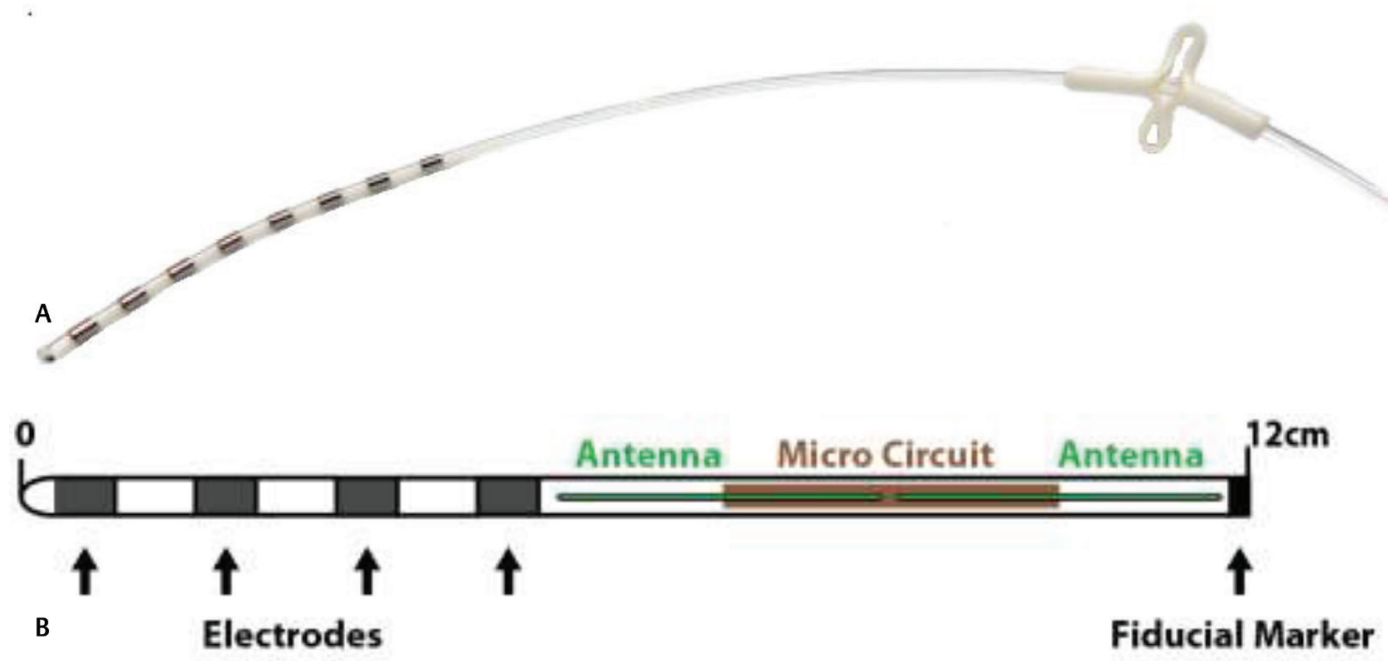

Fig. 1 The nanoelectrode with introducer. (b) The Stimwave implantable neural stimulator (property of Stimwave Technologies).

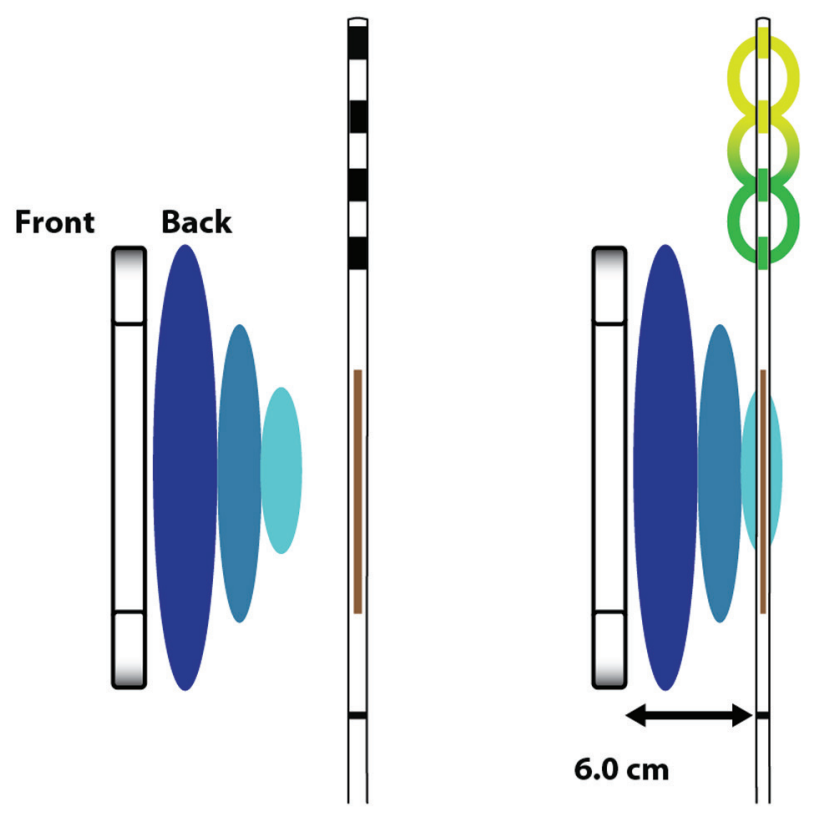

Fig. 2 Neurostimulator receiver (property of Stimwave Technologies).

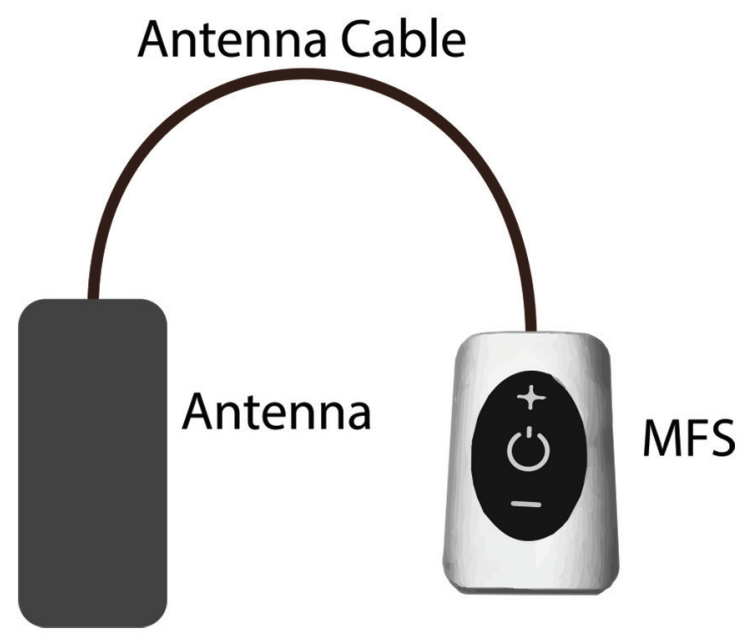

Fig. 3 External pulse generator (property of Stimwave Technologies). patient, without any connecting wires, anchors, and IPG. The INS receives the desired stimulation via a radiofrequency (RF) transmitting antenna inside the WPG. The implant utilizes RF energy of $915 \mathrm{MHz}$ to transfer the energy and the stimulation parameters as indicated for the patient.

Thus the only implanted component is a miniature electrode. This is passive electrically, and is operated by the transmitter in an external pulse generator (EPG), worn by the patient over a single layer of cloth. The INS receives the desired range of stimulation from the EPG via a radiofrequency $(R F)$ transmitting antenna (-Fig. 4). The implant and the EPG use RF energy at $915 \mathrm{MHz}$ to transfer power and selected stimulation parameters depending upon the patient's condition and appropriate clinical use. ${ }^{40}$

\section{Discussion}

SCS has been reported to be a safe therapeutic option for clinical application in patients with refractory angina. However, the conventional device had serious adverse events in several studies on SCS. 24,25,37,38,41-43 Traditional SCS has multiple implantable components that require multiple incisions and several anchors to keep the accessories in position. The procedure also requires longer time and possibly longer exposure to intraoperative radiation.

The IPG location is usually on the front of the chest (below clavicle) or in the abdomen/back, often seen as a bump with an overlying scar. In women, this may not be an acceptable cosmetic result.

On the other hand, wireless SCS (WSCS) requires only one device to be placed inside the patient and by percutaneous techniques. Implantation of the electrode with inbuilt miniature antenna is very minimalistic in surgical approach since WSCS does not require accessories to be implanted. For the same reason, revision procedures would be less invasive and explantation of the device would be much simpler compared with the traditional SCS equipment ( $\mathbf{- T a b l e ~} \mathbf{1}$ ).

WSCS avoids the tethering effects due to connection cables/ anchors and thus has less chances for lead migration, fracture, or displacement resulting in failures and complications. ${ }^{44}$ 

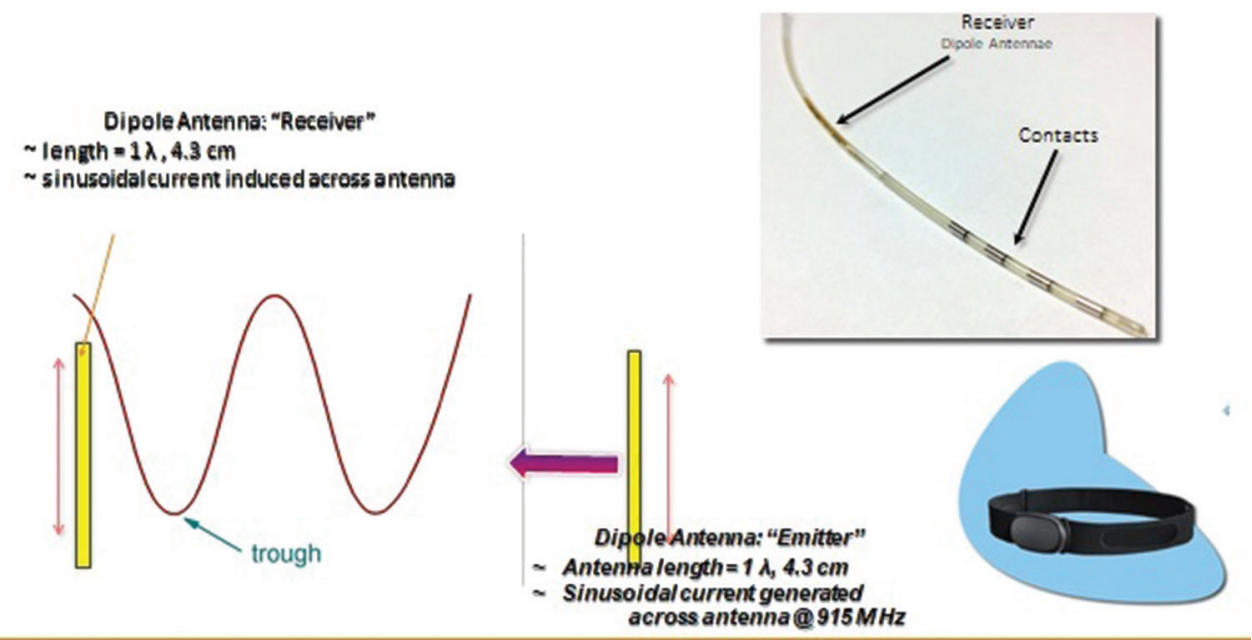

Fig. 4 Nano-electronics and mechanisms involved in the minimally invasive wireless neuromodulation.

Table 1 Differences between wireless and nonwireless spinal cord stimulation (SCS)

\begin{tabular}{|l|l|l|}
\hline Variable & Wireless SCS & Nonwireless SCS \\
\hline Implants & Only electrodes & Electrodes \\
\hline & Anchor & Implantable pulse generator \\
\hline & & Connections cables \\
\hline Incisions & One/two & Multiple anchors \\
\hline Bulk & Electrodes only & Multiple \\
\hline Trial & Not required & Required \\
\hline Scars & Small, single mostly & Multiple \\
\hline
\end{tabular}

Large-scale multicenter randomized studies are being currently undertaken to establish grounds for routine use of this simple, minimally invasive device. ${ }^{48}$ WSCS has the potential to reduce health care costs, hospital stay, and surgical trauma with improved acceptance from patients since the cosmetic result is much superior. Especially in patients with multiple comorbidities and limited life expectancy, this miniature device offers a better option to control chronic pain. RA is a condition that predominantly affects elderly people who have severe coexisting morbid conditions. WSCS can be the most appropriate choice to control their symptoms especially with a background of microvascular ischemia.

Table 2 Experience with wireless neuromodulation in women

\begin{tabular}{|l|l|l|l|l|l|}
\hline & Diagnosis & $\begin{array}{l}\text { Age } \\
(\mathbf{y})\end{array}$ & Procedure & Outcome & Ref. \\
\hline 1. & CRPS & 47 & PNS Radial and Median nerves & Relief & 47 \\
\hline 2. & Discopathy & 67 & SCS at T9 & Relief & 45 \\
\hline 3. & FBSS & 33 & SCS at T9 & Relief & 45 \\
\hline 4. & ON & 58 & Occipital nerve Stimulation & Relief & 46 \\
\hline 5. & FBSS 34 patients & & SCS & Relief & 48 \\
\hline
\end{tabular}

Abbreviations: CRPS, complex regional pain syndrome; FBSS, failed back surgery syndrome; ON, occipital neuralgia; PNS, peripheral nerve stimulation; SCS, spinal cord stimulation.

Wireless device from Stimwave (Stimwave Technologies, Fort Lauderdale, Miami, Florida) belongs to an advanced version of wireless technology and is programmable between 0 and $10,000 \mathrm{~Hz}$ frequency. It has been approved by FDA for SCS and peripheral nerve stimulation for several years now.

In several case illustrations, WSCS and wireless PNS provided effective pain relief. The technology demonstrated safety and feasibility in many instances with results comparable to the therapeutic efficacy of traditional SCS. ${ }^{45-48}$ Experience with wireless neuromodulation in a variety of chronic pain syndromes has been published in many reports (-Table 2 ).

\section{Conflict of Interest}

Dr. Tyler Perryman reports that he is Chairman and CEO of Stimwave Technologies Incorporated. In addition, Dr. Tyler Perryman has a patent 1. US9409029B2 Remote RF power system with low profile transmitting antenna 2. US9254393B2. Wearable antenna assembly 3. US9220897B2. Implantable lead 4. US9199089B2. Remote control of power or polarity selection for a neural stimulator. 5. US8849412B2. Microwave field stimulator. 6. US8903502B2. Methods and devices for modulating excitable tissue of the exiting spinal nerves. 7. US9409030B2. 
Neural stimulator system. 8. US15228715. Remote rf power system with low profile transmitting antenna. 9. US9522270B2. Circuit for an implantable device issued.

Dr. Slavin reports and confirms being a consultant/advisor for Abbott, Biotronik, Boston Scientific, Medtronic, Neuramodix, Nevro, Nuvectra, SPR, Stimwave, and Thermaquil, and has minor ownership or ownership option in Higgs Boson, Neuramodix, Stimwave, Thermaquil, and Vycor Medical.

\section{References}

1 Mehta PK, Bairey Merz CN, Treatment of stable angina in subjects with evidence of myocardial ischemia and no obstructive coronary artery disease. In: Bonow RO, Mann DL, Zipe DP, Libby P. Braunwald's Heart Disease: A Textbook of Cardiovascular Medicine, 8th ed. Philadelphia, PA: Saunders/Elsevier; 2008

2 Fox K, Garcia MA, Ardissino D, et al; Task Force on the Management of Stable Angina Pectoris of the European Society of Cardiology; ESC Committee for Practice Guidelines (CPG). Guidelines on the management of stable angina pectoris: executive summary: The Task Force on the Management of Stable Angina Pectoris of the European Society of Cardiology. Eur Heart J 2006;27(11):1341-1381

3 Kothawade K, Bairey Merz CN. Microvascular coronary dysfunction in women: pathophysiology, diagnosis, and management. Curr Probl Cardiol 2011;36(8):291-318

4 Mannheimer C, Camici P, Chester MR, et al. The problem of chronic refractory angina; report from the ESC Joint Study Group on the Treatment of Refractory Angina. Eur Heart J 2002;23(5):355-370

5 Henry TD, Satran D, Hodges JS, et al. Long-term survival in patients with refractory angina. Eur Heart J 2013; 34(34):2683-2688

6 Henry TD, Satran D, Jolicoeur EM. Treatment of refractory angina in patients not suitable for revascularization. Nat Rev Cardiol 2014;11(2):78-95

7 Statistics Canada. Canadian Community Health Survey (CCHS). 2002. www23.statcan.gc.ca/imdb/p2SV. Accessed June 1, 2019

8 McGillion M, Arthur HM, Cook A, et al. Canadian Cardiovascular SocietyCanadian Pain Society. Management of patients with refractory angina: Canadian Cardiovascular Society/Canadian Pain Society joint guidelines. Can J Cardiol 2012;28(2, Suppl):S20-S41

9 Bhatt $A B$, Stone PH. Current strategies for the prevention of angina in patients with stable coronary artery disease. Curr Opin Cardiol 2006;21(5):492-502

10 Thadani U. Recurrent and refractory angina following revascularization procedures in patients with stable angina pectoris. Coron Artery Dis 2004;15(Suppl 1):S1-S4

11 Williams B, Menon M, Satran D, et al. Patients with coronary artery disease not amenable to traditional revascularization: prevalence and 3-year mortality. Catheter Cardiovasc Interv 2010;75(6):886-891

12 British Cardiovascular Intervention Society Audit2014www. bcis.org.uk. Accessed June 1, 2019

13 Povsic TJ, Broderick S, Anstrom KJ, et al. Predictors of longterm clinical endpoints in patients with refractory angina. J Am Heart Assoc 2015;4(2):e001287

14 Mukherjee D, Bhatt DL, Roe MT, Patel V, Ellis SG. Direct myocardial revascularization and angiogenesis-how many patients might be eligible? Am J Cardiol 1999;84(5):598-600,A8

15 Chester M, Hammond C, Leach A. Long-term benefits of stellate ganglion block in severe chronic refractory angina. Pain 2000;87(1):103-105
16 van Kleef M, Staats P, Mekhail N, Huygen F. Chronic refractory angina pectoris. Pain Pract 2011;11(5):476-482

17 Latif OA, Nedeljkovic SS, Stevenson LW. Spinal cord stimulation for chronic intractable angina pectoris: a unified theory on its mechanism. Clin Cardiol 2001;24(8):533-541

18 Naver H, Augustinsson LE, Elam M. The vasodilating effect of spinal dorsal column stimulation is mediated by sympathetic nerves. Clin Auton Res 1992;2(1):41-45

19 Norrsell H, Eliasson T, Mannheimer C, et al. Effects of pacing-induced myocardial stress and spinal cord stimulation on whole body and cardiac norepinephrine spillover. Eur Heart J 1997;18(12):1890-1896

20 Sanderson JE, Tomlinson B, Lau MS, et al. The effect of transcutaneous electrical nerve stimulation (TENS) on autonomic cardiovascular reflexes. Clin Auton Res 1995;5(2):81-84

21 Hautvast RW, Blanksma PK, DeJongste MJ, et al. Effect of spinal cord stimulation on myocardial blood flow assessed by positron emission tomography in patients with refractory angina pectoris. Am J Cardiol 1996;77(7):462-467

22 Jessurun GA, Tio RA, De Jongste MJ, Hautvast RW, Den Heijer $\mathrm{P}$, Crijns HJ. Coronary blood flow dynamics during transcutaneous electrical nerve stimulation for stable angina pectoris associated with severe narrowing of one major coronary artery. Am J Cardiol 1998;82(8):921-926

23 Foreman RD, Linderoth B, Ardell JL, et al. Modulation of intrinsic cardiac neurons by spinal cord stimulation: implications for its therapeutic use in angina pectoris. Cardiovasc Res 2000;47(2):367-375

24 Börjesson M, Andrell P, Lundberg D, Mannheimer C. Spinal cord stimulation in severe angina pectoris-a systematic review based on the Swedish Council on Technology assessment in health care report on long-standing pain. Pain 2008;140(3):501-508

25 Taylor RS, De Vries J, Buchser E, Dejongste MJ. Spinal cord stimulation in the treatment of refractory angina: systematic review and meta-analysis of randomised controlled trials. BMC Cardiovasc Disord 2009;9:13

26 Apthorp GH, Chamberlain DA, Hayward GW. The effect of sympathectomy on the electrocardiogram and effort tolerance in angina pectoris. Br Heart J 1964;26:218-226

27 Melzack R, Wall PD. Pain mechanisms: a new theory. Science 1965;150(3699):971-979

28 Murphy DF, Giles KE. Dorsal column stimulation for pain relief from intractable angina pectoris. Pain 1987;28(3):365-368

29 Satran D, Traverse JH, Barsness GW, et al. Emerging therapies for refractory angina. Minn Med 2008;91(1):36-39

30 de Vries J, Foreman RD, DeJongste MJ. The anti-ischemic effects of electrical neurostimulation in the heart. Cleve Clin J Med 2007;74(Suppl 1):S42-S47

31 Buchser E, Durrer A, Albrecht E. Spinal cord stimulation for the management of refractory angina pectoris. J Pain Symptom Manage 2006;31(4, Suppl):S36-S42

32 Augustinsson LE. Spinal cord stimulation in peripheral vascular disease and angina pectoris. J Neurosurg Sci 2003;47(1, supplement (Suppl 1):37-40

33 DeJongste MJ, Tio RA, Foreman RD. Chronic therapeutically refractory angina pectoris. Heart 2004;90(2):225-230

34 Pan X, Bao H, Si Y, et al. Spinal cord stimulation for refractory angina pectoris: A systematic review and meta-analysis. Clin J Pain 2017;33(6):543-551

35 Turner JA, Loeser JD, Deyo RA, Sanders SB. Spinal cord stimulation for patients with failed back surgery syndrome or complex regional pain syndrome: a systematic review of effectiveness and complications. Pain 2004;108(1-2):137-147

36 Mekhail NA, Mathews M, Nageeb F, Guirguis M, Mekhail MN, Cheng J. Retrospective review of 707 cases of spinal cord stimulation: indications and complications. Pain Pract 2011;11(2):148-153 
37 Cameron T. Safety and efficacy of spinal cord stimulation for the treatment of chronic pain: a 20-year literature review. J Neurosurg 2004;100(3, Suppl Spine):254-267

38 Pineda A. Complications of dorsal column stimulation. J Neurosurg 1978;48(1):64-68

39 Slavin KV. Spinal stimulation for pain: future applications. Neurotherapeutics 2014;11(3):535-542

40 Tyler Perryman L, Larson P, Glaser J. Tissue depth study for a fully implantable, remotely powered and programmable wireless neural stimulator. Int J Nano Stud Technol 2016;S2 1-6

41 Hautvast RW, DeJongste MJ, Staal MJ. van Gilst WH, Lie KI. Spinal cord stimulation in chronic intractable angina pectoris: a randomized, controlled efficacy study. Am Heart J 1998;136(6):1114-1120

42 Eddicks S, Maier-Hauff K, Schenk M. Müller A, Baumann G, Theres $\mathrm{H}$. Thoracic spinal cord stimulation improves functional status and relieves symptoms in patients with refractory angina pectoris: the first placebo-controlled randomised study. Heart 2007;93(5):585-590

43 Zipes DP, Svorkdal N, Berman D, et al. Spinal cord stimulation therapy for patients with refractory angina who are not candidates for revascularization. Neuromodulation 2012;15(6):550-558, discussion 558-559

44 Yearwood TL, Perryman LT. Peripheral neurostimulation with a microsize wireless stimulator. Prog Neurol Surg 2015;29:168-191

45 Billet B, Hanssens K, De Coster O, et al. Wireless highfrequency dorsal root ganglion stimulation for chronic low back pain: a pilot study. Acta Anaesthesiol Scand 2018 (e-pub ahead of print)

46 Perryman LT, Speck B, Weiner RL. A novel wireless minimally invasive neuromodulation for the treatment of chronic intractable occipital neuralgia. J Neurol Stroke 2017;6(5):00213

47 Herschkowitz D, Kubias J. Wireless peripheral nerve stimulation for complex regional pain syndrome type I of the upper extremity: a case illustration introducing a novel technology. Scand J Pain 2018;18(3):555-560

48 North RB, Calodney A, Bolash R, et al. Redefining spinal cord stimulation "Trials": a randomized controlled trial using single-stage wireless permanent implantable devices. Neuromodulation 2019 (e-pub ahead of print) 